\section{A) Check for updates}

Cite this: Dalton Trans., 2020, 49 9632

Received 2nd April 2020,

Accepted 23rd June 2020

DOI: $10.1039 / \mathrm{d} 0 \mathrm{dt} 01236 \mathrm{j}$

rsc.li/dalton

\title{
Single crystal growth of water-soluble metal complexes with the help of the nano-crystallization method $\uparrow$
}

\author{
Ricardo Alvarez, Philipp P. Nievergelt, (D) Ekaterina Slyshkina, (D) Peter Müller, \\ Roger Alberto (D) and Bernhard Spingler (D) *
}

\begin{abstract}
The Nano-Crystallization method has been extensively tested for the growth of single crystals of cationic coordination compounds, which are soluble in water. All three studied, diverse metal complexes could be crystallized with the help of pipetting robots commonly used for the crystallization of proteins and the anion small molecule screen. It was furthermore possible to obtain for each positively charged complex several structures with different anions. In one case, together with literature data, a total of six salts with different anions could be assembled, which allowed an investigation of the influence of the counterions on the inter-cation metal-to-metal distance. The Nano-Crystallization method can be recommended for the single crystal growth of cationic coordination complexes, which are stable in water and have an aqueous solubility of at least $2 \mathrm{mM}$. This is the first publication dedicated solely to the single crystal growth of coordination complexes.
\end{abstract}

\section{Introduction}

In most cases, setting up the crystallization of a small molecule is a manual process. If done intentionally, a solution of the compound is prepared and then the conditions are changed in order to reach supersaturation, which is hopefully followed by crystallization. ${ }^{1}$ While there are dedicated publications that deal exclusively with the crystallization of organic compounds, ${ }^{2}$ there are no publications to the best of our knowledge that are solely dedicated to the growth of single crystals of coordination metal complexes (see however the following references for the (single) crystal growth of MOFs from aqueous solutions, ${ }^{3}$ for the high-throughput synthesis of crystalline MOF materials ${ }^{4}$ and for the measurement of microcrystals of reactive coordination complexes ${ }^{5}$ ). This is really surprising, as $57 \%$ of the entries in the Cambridge Structure Database $^{6}$ contain a metal ion. We have recently developed a crystallization screen consisting of 77 different anions and have successfully applied the screen for the crystallization of six out of seven very diverse organic cations, which were all

Department of Chemistry, University of Zurich, 8057 Zurich, Switzerland.

E-mail: spingler@chem.uzh.ch

$\dagger$ Electronic supplementary information (ESI) available: Detailed description and crystallographic data for $\mathbf{1 a - 1}, \mathbf{c}, \mathbf{2 a}, \mathbf{2 b}, \mathbf{4 a}-\mathbf{4 d}$, in CIF format, additional structural figures and experimental characterizations. CCDC 1986517-1986525. For ESI and crystallographic data in CIF or other electronic format see DOI: 10.1039/ dodt01236j water soluble to at least a concentration of $2 \mathrm{mM}^{7}$ The 96 different solutions of the screen are either mixed with the help of a pipetting robot $^{7 a}$ or just with a cheap multi-channel pipette under oil. ${ }^{7 b}$ Vapor diffusion of water from the crystallization drops either in the bigger reservoir ${ }^{7 a}$ or through the oil into the air, ${ }^{7 b}$ induces the growth of the crystals. The first coordination complex crystallized by this technique has just been reported. ${ }^{8}$

With coordination metal complex cations, the counteranion has an influence upon various structural aspects such as dimensionality, topology and nuclearity, and other parameters dependent on the structure, such as the magnetic behavior of cobalt(II), ${ }^{9}$ copper(II) ${ }^{10} \operatorname{zinc(II)},{ }^{11} \operatorname{silver(II),}{ }^{12}$ cadmium(II), ${ }^{13}$ mercury(II) ${ }^{14}$ and dysprosium(III) ${ }^{15}$ coordination complexes. It is a common feature of these studies that they are limited to simple anions, whose metal salts are already commercially available and which serve as starting materials for the complex formation. Bugris et al. described the calcium(II) complexes of two similar polyhydroxy carboxylates, gluconate and isosaccharinate. ${ }^{16}$ These two structures display very different shortest

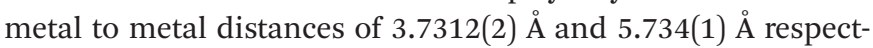
ively, because in the first case a $\mu$-oxo bridge formed by the carboxylate was present but not in the latter.

In the course of this study, we wanted to evaluate systematically the crystallization behavior of selected cationic coordination complexes using our newly developed NanoCrystallization technique. ${ }^{7 a}$ For this purpose, we chose the racemic chloride salts of cobalt(III) tris(bipyridine) $(\mathbf{1})^{17}$ and 


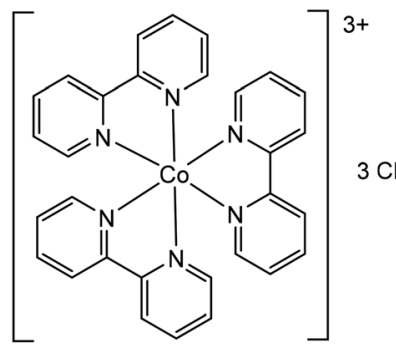

1

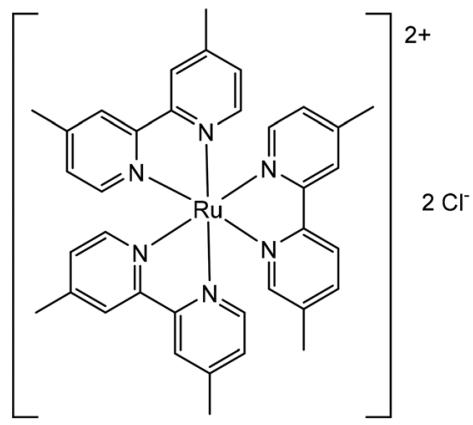

2

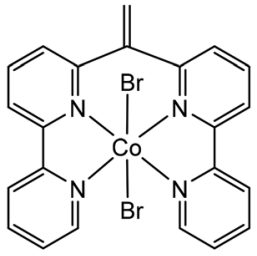

3

Fig. 1 The tested coordination complexes for single crystal growth by the anion exchange Nano-Crystallization method: [Co(III)(2,2'-bipyridine) ${ }_{3}$ ] (chloride) ${ }_{3}$ (1), [Ru(II)(4,4'-dimethyl-2,2'-bipyridine) $\left.)_{3}\right]\left(\right.$ chloride) ${ }_{2}$ (2), and Co(I)(6,6"-(ethene-1,1-diyl)di-2,2'-bipyridine)(bromide) 2 (3).

ruthenium(II) tris(4,4'-dimethyl-2,2'-bipyridine) $(2)^{18}$ as well as cobalt(II)(6,6"-(ethene-1,1-diyl)di-2,2'-bipyridine)(bromide) ${ }_{2}$ (3) as test candidates (Fig. 1). While complex 3 was expected to allow direct coordination of some exchanged anions to the metal center, this direct coordination mode was assumed to be unlikely in the case of the coordinatively saturated metal centers in $\mathbf{1}$ and 2. Cobalt(III) tris(bipyridine) and ruthenium(II) tris(bipyridine) complexes are important in many light-toenergy applications like dye-sensitized solar cells (DSSC). ${ }^{19}$ DSSCs use a wide band-gap semiconductor, which is sensitized to visible light by an adsorbed dye molecule and an electrolyte containing a redox mediator. ${ }^{20}$ Cobalt(III) tris(2,2'-bipyridine) complexes are used as high-performing dye-regenerating mediators in DSSC. Compared to iodide, the traditional mediator used in DSSC, cobalt complexes are noncorrosive to the metal cathodes and tend to compete less with the dye for visible light and most importantly have synthetically tunable redox potentials. ${ }^{19 a}$ Ruthenium(II) polypyridine complexes and their derivatives have been tested extensively as photosensitizers in DSSC. ${ }^{20 a, 21}$ Another area of use for ruthenium(II) trisbipyridine complexes is the excited-state proton-coupled electron transfer (PCET), in which two ruthenium(II) tris-bipyridine cations are connected by a salt bridge to facilitate the proton transfer. ${ }^{19 b}$ So far, only two crystal structures have been reported that contain the cobalt(III) tris(2,2'-bipyridine) cation with a simple anion. ${ }^{22}$ Analogously, only two reported crystal structures describe the cationic ruthenium(II) tris(4,4'dimethyl-2,2'-bipyridine) moiety. ${ }^{23}$ Facile generation of single crystals for these complex classes would be of utmost importance for many research directions.

\section{Experimental}

\subsection{General chemical procedures}

All reactions were done using standard laboratory glassware. Ruthenium(III) trichloride hydrate was purchased from Johnson Matthey, 4,4'-dimethyl-2,2'-bipyridyl ( $\geq 99 \%$ ) from Acros Organics, pentaamminechlorocobalt(III) chloride from Sigma Aldrich, 2,2'bipyridyl from TCI Chemicals, acetone ( $\geq 99.8 \%)$ from Merck, dimethyl sulfoxide (DMSO, $\geq 99.5 \%$ ), dichloromethane (DCM, $\geq 99 \%$ ), ether ( $\geq 99 \%$ ) from Sigma Aldrich, ethanol ( $\geq 99.8 \%$ ) from VWR Chemicals. All chemicals were used without further purification. Solvents were of p.a. grade. Aluminum oxide 90 (basic) for column chromatography activity level 1 purchased from Macherey-Nagel was used for purification. cis-Ru(DMSO) ${ }_{4} \mathrm{Cl}_{2}$ was synthesized on a $2 \mathrm{mmol}$ scale according to the literature in a yield of $69 \% .{ }^{24}$ The IR spectrum was recorded on a SpectrumTwo FT-IR Spectrometer (Perkin-Elmer) equipped with a Specac Golden Gate ${ }^{\mathrm{TM}}$ ATR accessory for neat samples. The frequencies are reported in wavenumbers $\left(\mathrm{cm}^{-1}\right)$.

Chromatography: Merck ALOX $60(40-63 \mu \mathrm{m})$ with the indicated solvent system. Thin layer chromatography (TLC): Merck TLC plates silica gel 60 on aluminum with the indicated solvent system; the spots were visualized by UV light (254 and $366 \mathrm{~nm}) .{ }^{1} \mathrm{H}-\mathrm{NMR}$ spectra were recorded on a Bruker AV-400 $(400 \mathrm{MHz})$, the coupling constants are given in Hz. Highresolution electrospray mass spectra (HR-ESI-MS) were recorded on a maXis QTOF-MS instrument (Bruker Daltonics $\mathrm{GmbH}$, Bremen, Germany). The samples were dissolved in a suitable solvent (e.g. MeOH) at a concentration of $c a .50 \mu \mathrm{g}$ $\mathrm{ml}^{-1}$ and analyzed via continuous flow injection $\left(2 \mu \mathrm{L} \mathrm{min}{ }^{-1}\right)$. The mass spectrometer was operated in the positive electrospray ionization mode at $4000 \mathrm{~V}$ capillary voltage, $-500 \mathrm{~V}$ endplate offset, with a $\mathrm{N}_{2}$ nebulizer pressure of 0.8 bar and dry gas flow of $4 \mathrm{~L} \mathrm{~min}^{-1}$ at $180^{\circ} \mathrm{C}$. MS acquisitions were performed in the mass range from $\mathrm{m} / \mathrm{z} 50$ to 2000 at 20000 resolution (full width at half maximum) and $1.0 \mathrm{~Hz}$ spectra rate. The mass analyzer was calibrated between $\mathrm{m} / \mathrm{z} 118$ and 2721 using an Agilent ESI-L low concentration tuning mix solution (Agilent, USA) at a resolution of 20000 and a mass accuracy below $2 \mathrm{ppm}$. All solvents used were purchased in best LC-MS qualities. Elemental analyses were acquired on a LECO Truespec CHNS(O)-microanalyser. The used HPLC system was a VWR Hitachi Chromaster with a diode array detector 5430 and a Reproshell $\mathrm{C}_{18}, 2.6 \mu \mathrm{m}, 75 \times 4.6 \mathrm{~mm}$ column (Dr Maisch $\mathrm{GmbH}$, Germany), which was kept at $40{ }^{\circ} \mathrm{C}$. The used gradient was $95 \% \mathrm{~A}$ (water with $0.1 \%$ formic acid) and $5 \% \mathrm{~B}$ (acetonitrile) changing linearly within 5.8 minutes to $100 \% \mathrm{~B}$, which was maintained for one minute. The aqueous solubilities of $\mathbf{1}$ 
and 2 were determined by gravimetry and HPLC respectively. For $1,50 \mu \mathrm{L}$ of a saturated solution of 1 were mixed together with $150 \mu \mathrm{L}$ of water in order to dilute the solution enough for the lyophilization process. After lyophilization, the remaining weight of 1 was determined. In order to estimate the errors of this procedure, a similar experiment was done with $125 \mu \mathrm{L}$ of a saturated sodium chloride solution. Based upon this and taking the concentration ${ }^{25}$ and the density ${ }^{26}$ of the saturated sodium chloride solution at $22{ }^{\circ} \mathrm{C}$ into account, the error of the gravimetric procedure was estimated to be $2 \%$. For 2 , an aqueous saturated solution was diluted 540-fold. Its concentration was determined by comparing it with a calibration line, which was generated by 10 -fold diluting an aqueous solution of $1.34 \mathrm{mg}$ of 2 in $1 \mathrm{ml}$ of water. Five different volumes between 1 and $20 \mu \mathrm{l}$ of the 10 -fold diluted solution of 2 were used to create the calibration line after manual integration. The error of the slope of the calibration line was calculated to be $0.5 \%$. The HPLC procedure could not be applied to compound 1, as it eluted too early together with the injection peak on our system.

\subsection{Synthesis of the starting coordination complexes 1-3}

Cobalt(III) tris(2,2'-bipyridine) chloride tris hydrate (1). ${ }^{17}$ In a two-necked round bottom flask $(10 \mathrm{~mL})$, equipped with a magnetic stir bar, a septum and a reflux condenser, pentaamminechlorocobalt(III) chloride $(79.5 \mathrm{mg}, 0.32 \mathrm{mmol}$ ) was suspended in a $30 \%$ methanol-water solution (2 mL). 2,2'Bipyridyl (148.4 mg, $0.95 \mathrm{mmol}$ ) was added and the purple suspension was heated to reflux $\left(95^{\circ} \mathrm{C}\right)$ until the TLC showed complete consumption of 2,2'-bipyridyl (8 hours). A clear orange brown solution was observed. The solvent was evaporated with a rotary evaporator after which the orange crude product was collected and further dried in vacuo (2 hours). The crude product was purified by thermal recrystallization. It was suspended in $3 \mathrm{~mL}$ EtOH and heated to $80{ }^{\circ} \mathrm{C}$ until a clear solution was observed. The clear orange solution was cooled to $23{ }^{\circ} \mathrm{C}$ and $1 \mathrm{~mL}$ of cyclohexane was added upon which a beige suspension was observed. The beige suspension was centrifuged. The mother liquor was removed, the beige solid collected and dried in vacuo to afford the desired product 1 as a beige solid (100 mg, $0.15 \mathrm{mmol}$ ) in a yield of $46 \%$. Purity: $>95 \%\left({ }^{1} \mathrm{H}-\mathrm{NMR}\right)$. TLC: $R_{\mathrm{f}}=0.52\left(\mathrm{MeOH} / \mathrm{CH}_{2} \mathrm{Cl}_{2} 3: 17\right) .{ }^{1} \mathrm{H}-\mathrm{NMR}$ $\left(\mathrm{D}_{2} \mathrm{O}\right): 8.82(\mathrm{dd}, J=7.7,1.0,2 \mathrm{H}) ; 8.53(\mathrm{td}, J=7.8,1.2,2 \mathrm{H})$; 7.79-7.75 (m, $2 \mathrm{H})$; 7.45 (d, $J=6.0,2 \mathrm{H})$. HR-ESI(+)-MS $\left(\mathrm{H}_{2} \mathrm{O}\right)$ : calc. for $\left[\mathrm{C}_{30} \mathrm{H}_{24} \mathrm{CoN}_{6}\right]^{2+}: 263.56910$, exp.: $263.56917(100 \%, \Delta=$ 0.26 ppm); calc. for $\left[\mathrm{C}_{20} \mathrm{H}_{16} \mathrm{CoN}_{4}\right]^{2+}: 185.53480$, exp.: 185.53461 $(28 \%, \Delta=0.98 \mathrm{ppm})$, calc. for $\left[\mathrm{C}_{30} \mathrm{H}_{24} \mathrm{CoN}_{6}\right]^{3+}: 175.71260$, exp.: $175.71252(22 \%, \Delta=0.47 \mathrm{ppm})$. Anal. calcd for $\left[\mathrm{Co}(\mathrm{bpy})_{3}\right]$ $\mathrm{Cl}_{3} \cdot 5.5 \mathrm{H}_{2} \mathrm{O}: \mathrm{C}, 49.16 ; \mathrm{H}, 4.81 ; \mathrm{N}, 11.47$. Found: $\mathrm{C}, 48.74 ; \mathrm{H}$, 4.67; N, 11.93. The measured powder XRD pattern of 1 is shown in Fig. S3. $\dagger$ The aqueous solubility of $\mathbf{1}$ was determined by gravimetry to be $461 \pm 9 \mathrm{mM}$.

Ruthenium(II) tris(4,4'-dimethyl-2, 2'-bipyridine) chloride tetrahydrate (2). ${ }^{18}$ cis-Ru(DMSO $)_{4} \mathrm{Cl}_{2}{ }^{24}(0.64 \mathrm{~g}, 1.33 \mathrm{mmol})$ and 4,4'-dimethyl-2,2'-bipyridine $(0.74 \mathrm{~g}, 4.02 \mathrm{mmol})$ were added to $25 \mathrm{~mL}$ of a $10 \%$ solution of water in ethylene glycol in a $100 \mathrm{~mL}$ round bottom flask equipped with a reflux condenser under the exclusion of light in $\mathrm{N}_{2}$ atmosphere and heated to reflux (oil bath, $120^{\circ} \mathrm{C}$ ) for 1 hour. After cooling to room temperature, the orange solution was diluted with water $(30 \mathrm{~mL})$ and then a saturated solution of ammonium hexafluorophosphate salt $(50 \mathrm{~mL})$ was added until complete precipitation. ${ }^{18 a}$ The orange solid was filtered off and dried under reduced pressure to yield the hexafluorophosphate salt of 2 (97\%, $1.22 \mathrm{~g}, 1.29 \mathrm{mmol})$ as orange crystals. IR (neat): 3595w, 2928w, 1620m, 1552w, 1479w, 1446w, 1304w, 1241w, 1038w, 988m, 972m, 821s. [Ru(II) $\left.\left(4,4^{\prime} \text {-dimethyl-2,2'-bipyridine }\right)_{3}\right] \mathrm{Cl}_{2}$ (2) was synthesized as the tetrahydrate from the hexafluorophosphate salt on a $1.3 \mathrm{mmol}$ scale according to the literature in a yield of $68 \%{ }^{18 a}$ Anal. calc. for $\mathrm{C}_{36} \mathrm{H}_{36} \mathrm{~N}_{6} \mathrm{RuCl}_{2}\left(\mathrm{H}_{2} \mathrm{O}\right)_{4}$ (796.76): C 54.27, H 5.57, N 10.55, found: C 54.19, H 5.59, N 10.42. The aqueous solubility of 2 was determined by HPLC to be $309.4 \pm 1.3 \mathrm{mM}$.

Preparation of [Co(II)(6,6"-(ethene-1,1-diyl)di-2,2'-bipyridine) (bromide) $)_{2}$ ] (3). To a suspension of $\mathrm{MePPh}_{3} \mathrm{Br}$ (154 mg, $0.423 \mathrm{mmol}, 1.43$ eq.) in $4.5 \mathrm{~mL}$ THF was added $\mathrm{KO} t \mathrm{Bu}$ (52.4 mg, $0.444 \mathrm{mmol}, 1.5$ eq.) in one portion and the resulting yellowish suspension was stirred for 1 hour at RT. Afterwards, di([2,2'-bipyridin]-6-yl)methanone ${ }^{27}$ (100 mg, $0.296 \mathrm{mmol}, 1.0$ eq.) in $4 \mathrm{~mL}$ THF was added dropwise over a period of 10 minutes and the resulting brown solution was stirred for another 4 hours at RT. Upon full conversion, the reaction mixture was quenched with $\mathrm{MeOH}$ and diluted with water. The two phases were separated and the aqueous layer was extracted 3 times with DCM. The combined organic layers were dried over $\mathrm{MgSO}_{4}$ and concentrated under reduced pressure to afford the crude product as a yellow oil. The crude product 6,6"-(ethene-1,1-diyl)di-2,2'-bipyridine was purified over basic ALOX (hexane/ethylacetate: $24: 1$ ) to afford $60.2 \mathrm{mg}(61 \%)$ of the pure product as a white solid. ${ }^{1} \mathrm{H}$ NMR: $(400 \mathrm{MHz}$, $\left.\mathrm{CD}_{3} \mathrm{CN}\right): 8.66$ (ddd, $\left.J=4.8,1.7,0.9,2 \mathrm{H}\right) ; 8.41-8.34(\mathrm{~m}, 4 \mathrm{H})$; $7.89(\mathrm{t}, J=7.9,2 \mathrm{H}) ; 7.82(\mathrm{td}, J=7.6,1.9,2 \mathrm{H}) ; 7.53(\mathrm{dd}, J=7.7$, $0.9,2 \mathrm{H}) ; 7.36$ (ddd, $J=7.5,4.7,1.2,2 \mathrm{H}) ; 6.25$ (s, 2H). HR-ESI (+)-MS: calc. for $\left[\mathrm{C}_{22} \mathrm{H}_{17} \mathrm{~N}_{4}\right]^{+}$: 337.14477, exp.: 337.14430 .

To a solution of $6,6^{\prime \prime}$-(ethene-1,1-diyl)di-2,2'-bipyridine (296 mg, $0.748 \mathrm{mmol}, 1.0$ eq.) in $12 \mathrm{~mL}$ acetonitrile was added $\mathrm{CoBr}_{2}$ (155 mg, $0.711 \mathrm{mmol}, 0.95$ eq.) in one portion and the resulting red suspension was stirred for 3 hours at RT. The red precipitate was collected on a P3 glass filter frit and dried under HV for several hours to obtain $316 \mathrm{mg}$ (76\%) of the desired product 3 as a red solid. HR-ESI-MS: calc. for [M $2 \mathrm{Br}]^{2+}$ : 197.53480, exp.: 197.53501. Anal. calcd for [Co $\left.\left(\mathrm{bpy}_{2} \mathrm{CCH}_{2}\right) \mathrm{Br}_{2}\right] \cdot 1.5 \mathrm{H}_{2} \mathrm{O}(\%): \mathrm{C}, 45.39 ; \mathrm{H}, 3.29 ; \mathrm{N}, 9.62$. Found: C, 45.44; H, 3.26; N, 9.52.

\subsection{Crystallographic procedures}

The crystallization experiments were done as previously descri$\operatorname{bed}^{7 a}$ using a Gryphon LCP nano-drop handler from Art Robbins Instruments in ARI Intelli-Plates 96-3 LVR. $500 \mathrm{~nL}$ of a stock solution of the cation to be crystallized ( $90 \%$ maximal saturation in water) were mixed with $500 \mathrm{~nL}$ of the stock solutions of the sodium and potassium salts and equilibrated against $75 \mu \mathrm{L}$ of the stock solution of the same sodium or potassium salt via vapor diffusion. The screen contains 77 
different sodium or potassium salts with a total of 96 different conditions and each coordination complex was tested for crystallization under those 96 conditions. The plates were incubated for 5-16 days at $20{ }^{\circ} \mathrm{C}$. The Rock Imager 1000 took a picture of each well with normal light (immediately after setting up the plate and then after 2, 5, 10 and 16 days) and cross polarized light (immediately after setting up the plate and then after 5, 10 and 16 days).

Crystallographic data were collected at 160.0(1) K (with the exception of $100.00(11) \mathrm{K}$ for $\mathbf{2 b}$ ) on a Rigaku OD XtaLAB Synergy Dualflex diffractometer equipped with a Pilatus $200 \mathrm{~K}$ detector and both PhotonJet $\mathrm{Mo} \mathrm{K}_{\alpha}$ and $\mathrm{Cu} \mathrm{K}_{\alpha}$ sources. Suitable crystals were covered with oil (Infineum V8512, formerly known as Paratone $\mathrm{N}$ ), placed on a nylon loop that is mounted on a CrystalCap Magnetic ${ }^{\mathrm{TM}}$ pin (Hampton Research) and immediately transferred to the diffractometer. The program suite CrysAlis ${ }^{\text {Pro }}$ was used for data collection, numerical and multi-scan absorption correction as well as data reduction. ${ }^{28}$ Each structure was solved with direct methods using ShelxT ${ }^{29}$ and was refined by full-matrix least-squares methods on $F^{2}$ with SHELXL-2014 ${ }^{30}$ using the OLEX2 GUI. ${ }^{31}$ Graphical output was produced with the help of the program Mercury $^{32}$ and the calculations of the geometry were done with the program Platon. ${ }^{33}$ For $1 \mathrm{a}$, a $7 \mathrm{keV}$ threshold was applied for the hybrid pixel Pilatus detector ${ }^{34}$ in order to minimize the $\mathrm{X}$-ray fluorescence caused by the cobalt complex being irradiated with copper radiation. ${ }^{35}$ Additionally, the crystals of $\mathbf{1 a}$ were twinned by a $180^{\circ}$ rotation around the $a$-axis. The twin ratio was 69:31 and the two merged twin components were handled with the HKLF5 command in ShelxL. For 1c, two complexes plus 15 water molecules and additional a half-occupied sodium chloride were found in the asymmetric unit, which corresponds to the unit cell (space group $P 1$ ). Several water molecules were half occupied; their hydrogen atoms could not be found. One half occupied water molecule and a half-occupied sodium are located on the same position. Several restraints for the hydrogen atoms had to be used. For $\mathbf{2 a}$, the squeeze routine within Platon had to be used. ${ }^{36}$ For $4 \mathbf{c}$, unexpectedly the spherical absorption correction was much better in terms of $I / \sigma(I)$ and $R_{\text {int }}$ than the Gaussian or the numerical absorption correction. CCDC entries 1986517-1986525† contain the supplementary crystallographic data for this paper. Powder X-ray diffraction (PXRD) patterns were recorded on a STOE STADI $\mathrm{P}$ diffractometer equipped with a DECTRIS MYTHEN 1K detector in transmission mode using a Ge monochromator for Mo radiation $(0.70930 \AA) .{ }^{37}$ Background correction of the recorded PXRD pattern was done with help of the software QUALX2.0. ${ }^{38}$ Simulated PXRD pattern based on the single crystal analyses were generated with the help of the program Mercury. ${ }^{32}$

\section{Results \& discussion}

The three chosen cationic (or cationic after anion dissociation), water-soluble metal complexes (1-3) were all subjected to the same high throughput screening Nano-
Crystallization method,,$^{7 a}$ in which $500 \mathrm{nl}$ of a $90 \%$ saturated aqueous solution of the complexes were mixed with $500 \mathrm{nl}$ of an aqueous sodium salt solution containing the desired anion, which was added by a pipetting robot. Subsequently, this mixture was equilibrated by vapor diffusion against an excess of the same sodium salt solution. This procedure was repeated for each coordination complex with 95 different anion salt solutions to finally yield a completely filled 96-well crystallization plate with 96 different crystallization trials starting from one metal complex solution. The plates were incubated for 5-16 days at $20{ }^{\circ} \mathrm{C}$ in an imaging system. The Rock Imager 1000 took a picture of each well with normal light and cross polarized light. In the following, the results will be discussed for each obtained individual coordination complex moiety.

\subsection{Crystallization of the cobalt(III) tris(2,2'-bipyridine) triscationic unit}

Starting from cobalt(III) tris(2,2'-bipyridine) chloride, single crystals were obtained after mixing with either a $0.7 \mathrm{M}$ solution of sodium dicyanamide, a $2.27 \mathrm{M}$ solution of disodium $\mathrm{DL}^{-}$ malate or a $2.92 \mathrm{M}$ solution of disodium L-malate. All crystallographic data are summarized in Table $\mathrm{S} 1 . \dagger$

The aqueous mixture of cobalt(III) tris(2,2'-bipyridine) trichloride and sodium dicyanamide yielded crystals of cobalt(II) tris(2,2'-bipyridine) dicyanamide chloride-tetrahydrate (1a) in the hexagonal space group P6/mcc (Fig. 2). A $7 \mathrm{keV}$ threshold was applied for the hybrid pixel Pilatus detector ${ }^{34}$ in order to minimize the X-ray fluorescence caused by the cobalt complex being irradiated with copper radiation. ${ }^{35}$ The cobalt center in 1a was assigned without any doubt to be a $\mathrm{Co}(\mathrm{II})$, because the $\mathrm{Co}-\mathrm{N}$ bond length in 1a is 2.1259(16) $\AA$. This value is perfectly in line with the range of $\mathrm{Co}(\mathrm{II})-\mathrm{N}$ bond lengths between $2.117(8)$ and 2.141(7) $\AA$ in $\left[\mathrm{Co}\left(\right.\right.$ II) $\left.(\mathrm{bpy})_{3}\right] \mathrm{Cl}_{2} \cdot{ }^{39}$ On the other side, $\left[\mathrm{Co}(\text { III)(bpy })_{3}\right]$ $\mathrm{Cl}_{3}$ was reported to have Co-N bond lengths between 1.928(3)$1.939(3) \AA^{22 b}$ Synthetic experiments on a $0.4 \mathrm{~mL}$ scale revealed that the yield of this Co(II) complex is less than $10 \%$. We postulate that the used dicyanamide anion is responsible for this reduction. The starting material cobalt(III) tris(2,2'-bipyridine) chloride (1) was analysed by elemental analysis and PXRD, but no signs for a cobalt(II) impurity could be found in $\mathbf{1}$.

Single, red crystals of cobalt(III) bis(2,2'-bipyridine) DL-malate-decahydrate $(\mathbf{1 b})$ were obtained by vapor diffusion of a mixture of a $90 \%$ saturated solution of complex 1 and a $2.27 \mathrm{M}$ solution of disodium DL-malate against a reservoir of a $2.27 \mathrm{M}$ solution of disodium DL-malate. During crystallization a ligand exchange took place, whereby one 2,2'-bipyridine was replaced by a D- or L-malate anion. The resulting cobalt(III) bis(2,2'-bipyridine) DL-malate crystallized in the monoclinic space group I2/a (Fig. 2). The malate ligand coordinates as a bidentate trianion to the cobalt to yield a neutral complex overall. The substitution of one 2,2'-bipyridyl (bpy) (or the related 1,10-phenanthroline, phen) ligand within a cobalt(III)(bpy) $)_{3}$ or cobalt(III)(phen) $)_{3}$ complex by a dianionic $\alpha$-hydroxycarboxylate has been reported before. ${ }^{40}$

Single, red crystals of cobalt(III) bis(2,2'-bipyridine) L-malate $9.25\left(\mathrm{H}_{2} \mathrm{O}\right) \cdot 0.25(\mathrm{NaCl})$ (1c) were obtained by vapor diffusion of a mixture of a $90 \%$ saturated solution of 1 and a 

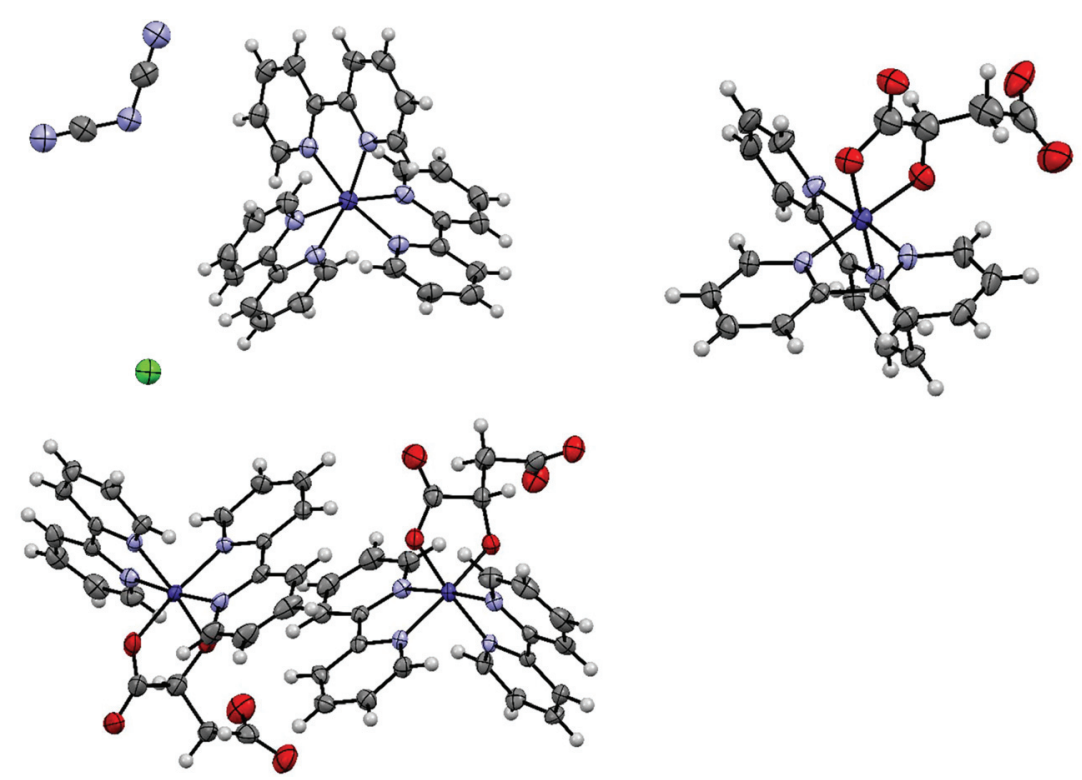

Fig. 2 Displacement ellipsoid representation of 1a (top left), 1b (top right) and 1c (lower left). Ellipsoids are drawn at 50\% probability. Disordered parts and water molecules are omitted for clarity.

2.92 $\mathrm{M}$ solution of disodium L-malate against a reservoir of a 2.92 M solution of disodium L-malate. Again, during crystallization a ligand exchange took place, whereby one 2,2'-bipyridine was replaced by one bidentate L-malate trianion. The resulting cobalt(III) bis(2,2'-bipyridine) L-malate crystallized in the triclinic, chiral space group $P 1$. Both delta and lambda forms of cobalt(III) bis(2,2'-bipyridine) L-malate are present in the crystal in a $1: 1$ ratio.

In the crystallization trials leading to the red complexes $\mathbf{1 b}$ and 1c, additionally yellow crystals could be seen and were confirmed by single crystal analysis to be the already published crystal structure of starting material $1 .^{22 b}$ Microscope images of the two crystallization trials leading to compounds $\mathbf{1}$ as well as $\mathbf{1 b}$ and $\mathbf{1 c}$ respectively are shown in Fig. S6 and S8. $\dagger$

\subsection{Crystallization of the ruthenium(II) tris( $\left(4,4^{\prime}\right.$-dimethyl-2,2'-} bipyridine) dicationic unit

Single crystals containing the ruthenium(II) tris( $4,4^{\prime}$-dimethyl2,2 '-bipyridine) dication were obtained from a mixture of a $90 \%$ saturated aqueous solution of ruthenium(II) $\operatorname{tris}\left(4,4^{\prime}\right.$ dimethyl-2,2'-bipyridine) chloride and either a $0.73 \mathrm{M}$ solution of disodium fumarate or a $1.57 \mathrm{M}$ solution of sodium saccharinate. All crystallographic data are summarized in Table S2. $\dagger$

The asymmetric unit of ruthenium(II) tris(4,4'-dimethyl-2,2'bipyridine).(hydrogenfumarate).(hemifumarate) (tetrahydrate) 2a consists of one ruthenium(II) tris(4,4'-dimethyl-2,2'-bipyridine) dication, one hydrogenfumarate anion, half a fumarate dianion and four water molecules (Fig. 3). The asymmetric

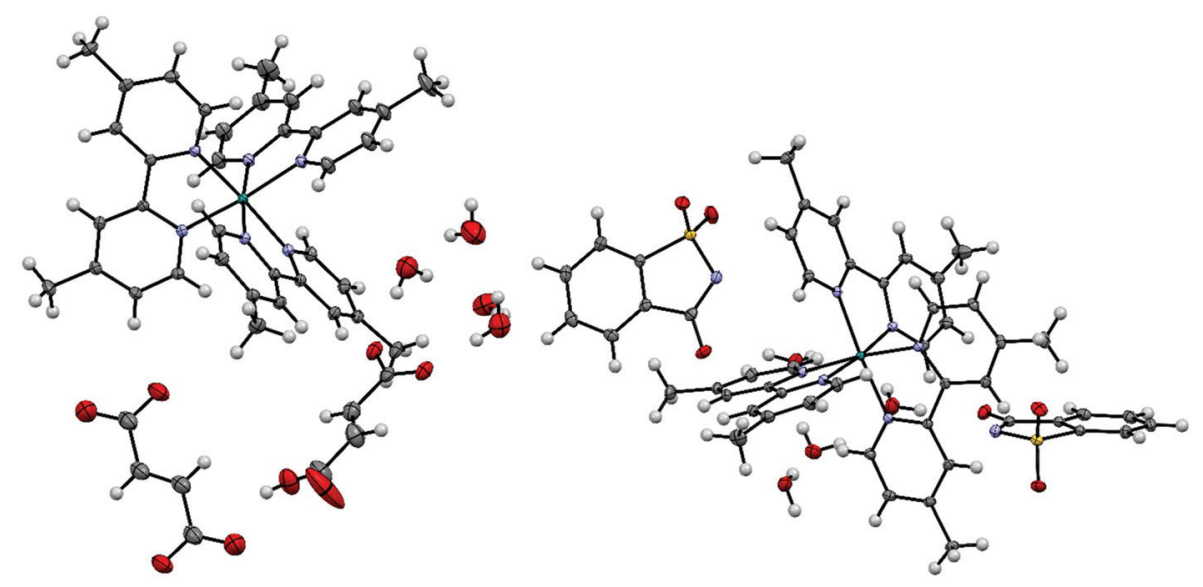

Fig. 3 Displacement ellipsoid representation of $2 a$ (left) and $\mathbf{2 b}$ (right). Ellipsoids are drawn at $50 \%$ probability. An inversion center symmetry operation has been applied to form the complete fumarate anion. The smaller ellipsoids of $\mathbf{2 b}$, compared with the other structures, are caused by the lower measurement temperature of $100 \mathrm{~K}$ instead of $160 \mathrm{~K}$. 
unit in the case of $\mathbf{2 b}$ consists of one ruthenium(II) tris( $4,4^{\prime}$ dimethyl-2,2'-bipyridine) dication, two saccharinate anions and four water molecules. Compound $\mathbf{2 b}$ was also synthesized on a macroscopic $(0.13 \mathrm{mmol})$ scale from the chloride salt 2 with the help of an anion exchange column in a yield of $84 \%$ (see Chapter S5†).

\subsection{Crystallization of the $\operatorname{Co}(\mathrm{II})\left(6,6^{\prime \prime}\right.$-(ethene-1,1-diyl)di-2,2'- bipyridine)(bromide) $)_{2}$ (3) complex}

The starting complex for the crystallizations was always cobalt(II) (6,6"-(ethene-1,1-diyl)di-2,2'-bipyridine)(bromide) ${ }_{2}$ (3). We expected that one or two bromide ligands might dissociate, thereby yielding a cationic complex, which might be a suitable candidate for our Anion screen. Unexpectedly, all obtained crystal structures contained the cobalt(II) bis(2,2'-bipyrid-6'-yl) ketone dication. It seems that, when complex (3) is dissolved in water, its double bond is oxidatively cleaved under aerobic conditions, resulting in the carbonyl group at the bridging position of the products 4 . The hypothesis is supported by various publications, in which cobalt complexes are reported to catalyze the oxidative cleavage of terminal double bonds by molecular oxygen. ${ }^{41}$ Single crystals containing the cobalt(II) bis (2,2'-bipyrid-6'-yl)ketone dication were obtained from a mixture of a $90 \%$ saturated aqueous solution of $\operatorname{Co}(\mathrm{II})\left(6,6^{\prime \prime}-\right.$ (ethene-1,1-diyl)di-2,2'-bipyridine)(bromide) ${ }_{2}$ and the same volume of either a $0.15 \mathrm{M}$ solution of sodium $p$-toluenesulfonate (4a), a $0.725 \mathrm{M}$ solution of disodium fumarate (4b), a $2 \mathrm{M}$ solution of sodium tetrafluoroborate $(4 \mathrm{c})$ or a $0.06 \mathrm{M}$ solution of disodium terephthalate (4d). All crystallographic data are summarized in Table S3.†

The asymmetric unit of $\mathbf{4 a}$ contains a cobalt(II) bis(2,2'bipyrid-6'-yl)ketone dication with an octahedral metal center coordinated by one $p$-toluenesulfonate anion and a water molecule. The remaining charge is compensated by a second free $p$-toluenesulfonate anion; additionally, there are four water molecules in the asymmetric unit (Fig. 4).

The asymmetric unit of $\mathbf{4 b}$ contains a cobalt(II) bis(2,2'bipyrid-6'-yl)ketone dication, one fumarate dianion and 2.25 water molecules (Fig. 4). The octahedral cobalt center is coordinated by the tetradendate ligand and two fumarate anions, where the latter bridge adjacent cobalt centers to form an infinite 1D-chain. The asymmetric unit of $\mathbf{4 c}$ consists of one cobalt(II) bis(2,2'-bipyrid-6'-yl)ketone dication, two tetrafluoroborate anions and two water ligands (Fig. 5). The octahedral
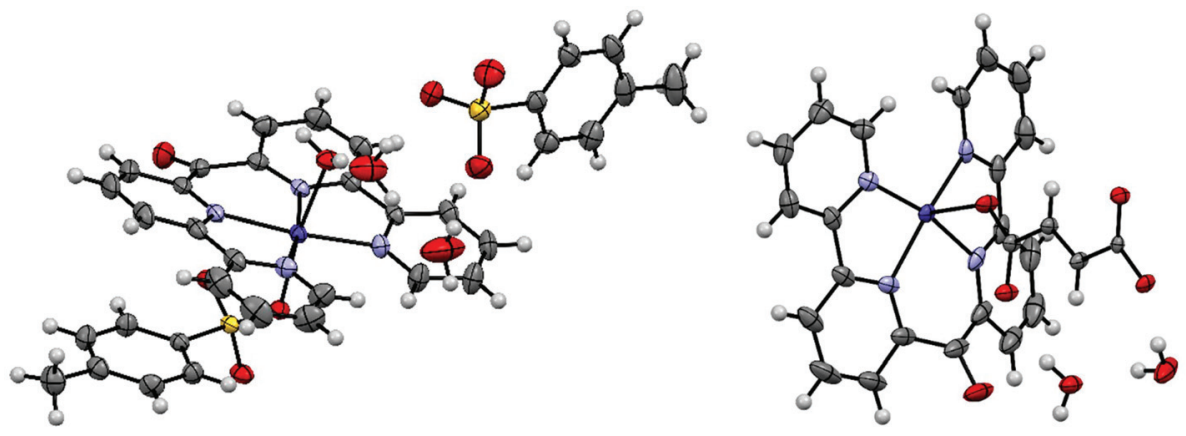

Fig. 4 Displacement ellipsoid representation of $4 a$ (left) and $4 b$ (right), ellipsoids drawn at $50 \%$ probability. One disordered water molecule in $4 a$ is omitted for clarity.
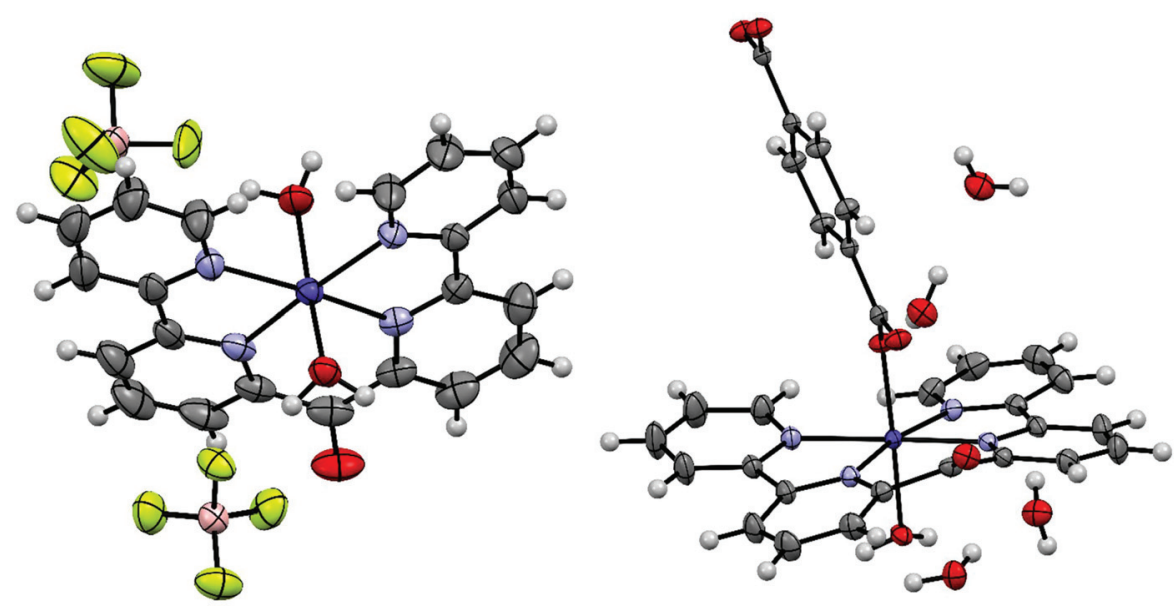

Fig. 5 Displacement ellipsoid representation of 4 c (left) and 4 d (right). Ellipsoids are drawn at $50 \%$ probability. For 4 d, the complete terephthalate ligand, which is created by a center of inversion, is shown for clarity. The free terephthalate dianion is omitted for clarity. 
Table 1 Variation of metal to metal distances in cobalt(II) bis(2,2'-bipyrid-6'-yl)ketone complexes as a function of present anion, sorted by the shortest metal-to-metal distance. The anion vdW volumes were calculated with the help of the program MarvinSketch ${ }^{43}$

\begin{tabular}{|c|c|c|c|c|c|}
\hline Compound & Anion & $\begin{array}{l}\text { Shortest cobalt-to- } \\
\text { cobalt distance }\end{array}$ & Axial metal coordination & $\begin{array}{l}\text { Anion vdW } \\
\text { volume }\left[\AA^{3}\right]\end{array}$ & Ref. \\
\hline $4 d$ & Terephthalate & $6.8324(3)$ & $\begin{array}{l}\text { Terephthalate bridged two cobalt metals, } \\
\text { on the other side water that is bridged by } \\
\text { one terephthalate to another water bound to Co }\end{array}$ & 133 & This work \\
\hline $4 a$ & Tosylate & $7.3475(3)$ & Tosylate on one side, water on the other & 141 & This work \\
\hline \multirow[t]{2}{*}{$4 \mathrm{c}$} & Tetrafluoroborate & $7.9998(8)$ & Water molecules on both sides & 54 & This work \\
\hline & Perchlorate & $8.0982(9)$ & Water molecules on both sides & 57 & 44 \\
\hline
\end{tabular}

cobalt is coordinated by the ligand and two axially coordinated water molecules.

The asymmetric unit of $\mathbf{4 d}$ consists of one cobalt(II) bis(2,2'bipyrid-6'-yl)ketone dication with only half of the coordinated terephthalate ligand, one coordinated and three free water molecules and another half of a free terephthalate dianion (Fig. 5). Each terephthalate species sits on a center of inversion.

\subsection{Variation of metal-to-metal distances caused by the presence of the different anions in six crystal structures containing the cobalt(II) bis(2,2'-bipyrid-6'-yl)ketone dication}

The modulation of the metal-to-metal distance is of great importance for the magnetic properties in certain supramolecular molecular metal complexes. ${ }^{42}$ Therefore, we asked ourselves, whether the Nano-Crystallization method could generate a diverse collection of coordination compounds that contain the same cationic metal complex with different anions. Each salt would be expected to have a different minimal metal-to-metal distance. Including this work, there are six crystal structures known that contain cobalt(II) complexes with the bis(2,2'-bipyrid-6'-yl)ketone ligand. This unique assembly of six coordination complexes, all having a $\mathrm{N}_{4} \mathrm{O}_{2}$ coordination environment, allows to study the influence of the introduced anion on the metal-to-metal distances (Table 1, see Table $\mathrm{S} 4 \dagger$ for an extended listing of metal-to-metal distances). From the data, it is clear that the shortest metal-to-metal distance does not correlate with the vdW volume of the anions. The shortest cobalt-to-cobalt distance among all six studied compounds, in $\mathbf{4 d}$, is present between neighboring complexes, which are not bridged by any ligand. The second shortest distance, in $\mathbf{4 a}$, is between two cobalt centers, which are bridged by an aqua ligand, which makes one hydrogen bond to a $\kappa O: \kappa O^{\prime}$ bridging sulfonate group of the tosylate anion, that is coordinating to the next cobalt center.

\section{Conclusion}

For all three tested metal coordination complexes, the NanoCrystallization method was able to generate novel single crystal structures with different anions, in which at least one of the original halide anions was replaced. This method can be rec- ommended for cationic coordination complexes, which are stable in water and have an aqueous solubility of at least 2 $\mathrm{mM}$. The shortest metal-to-metal distance was found to be purely dependent upon the interaction of the anion within the crystalline lattice and not upon the vdW size of the anion (Table 1).

\section{Conflicts of interest}

The University of Zurich has a license agreement with Molecular Dimensions Ltd, which states that Molecular Dimension Ltd has the right to sell the Anion Screen.

\section{Acknowledgements}

We thank the University of Zurich and the R'Equip programme of the Swiss National Science Foundation (project no. 206021_164018) for financial support. We thank Esmael Balaghi for measuring the PXRD, Viviane Grange for measuring the elemental analyses, Franziska Rahn and Matthias Berchtold for help with the HPLC measurements and Prof. Dr Anthony Linden for a critical reading of the manuscript.

\section{References}

1 (a) B. Spingler, S. Schnidrig, T. Todorova and F. Wild, CrystEngComm, 2012, 14, 751-757; (b) P. P. Nievergelt and B. Spingler, CrystEngComm, 2017, 19, 142-147.

2 (a) H.-H. Tung, E. L. Paul, M. Midler and J. A. McCauley, Crystallization of Organic Compounds: An Industrial Perspective, John Wiley \& Sons, Inc., 2009; (b) R. J. Davey, S. L. Schroeder and J. H. ter Horst, Angew. Chem., Int. Ed., 2013, 52, 2166-2179; (c) Y. Tamura, H. Takezawa, Y. Domoto and M. Fujita, Chem. Lett., 2018, 47, 617-619; (d) N. Wada, R. D. Kersten, T. Iwai, S. Lee, F. Sakurai, T. Kikuchi, D. Fujita, M. Fujita and J. K. Weng, Angew. Chem., Int. Ed., 2018, 57, 3671-3675; (e) A. Tyler, R. Ragbirsingh, C. McMonagle, P. Waddell, S. Heaps, J. Steed, P. Thaw, M. Hall and M. Probert, ChemRxiv, 2019, 11366054. 
3 (a) I. A. Ibarra, P. A. Bayliss, E. Pérez, S. Yang, A. J. Blake, H. Nowell, D. R. Allan, M. Poliakoff and M. Schröder, Green Chem., 2012, 14, 117-122; (b) P. A. Bayliss, I. A. Ibarra, E. Pérez, S. Yang, C. C. Tang, M. Poliakoff and M. Schröder, Green Chem., 2014, 16, 3796-3802; (c) B. Saccoccia, A. M. Bohnsack, N. W. Waggoner, K. H. Cho, J. S. Lee, D.-Y. Hong, V. M. Lynch, J.-S. Chang and S. M. Humphrey, Angew. Chem., Int. Ed., 2015, 54, 5394-5398; (d) K. Sumida, K. Liang, J. Reboul, I. A. Ibarra, S. Furukawa and P. Falcaro, Chem. Mater., 2017, 29, 2626-2645.

4 (a) E. Biemmi, S. Christian, N. Stock and T. Bein, Microporous Mesoporous Mater., 2009, 117, 111-117; (b) P. J. Kitson, R. J. Marshall, D. Long, R. S. Forgan and L. Cronin, Angew. Chem., Int. Ed., 2014, 53, 12723-12728; (c) M. L. Kelty, W. Morris, A. T. Gallagher, J. S. Anderson, K. A. Brown, C. A. Mirkin and T. D. Harris, Chem. Commun., 2016, 52, 7854-7857; (d) S. M. Moosavi, A. Chidambaram, L. Talirz, M. Haranczyk, K. C. Stylianou and B. Smit, Nat. Commun., 2019, 10, 539.

5 C. G. Jones, M. Asay, L. J. Kim, J. F. Kleinsasser, A. Saha, T. J. Fulton, K. R. Berkley, D. Cascio, A. G. Malyutin, M. P. Conley, B. M. Stoltz, V. Lavallo, J. A. Rodríguez and H. M. Nelson, ACS Cent. Sci., 2019, 5, 1507-1513.

6 R. Taylor and P. A. Wood, Chem. Rev., 2019, 119, 94279477.

7 (a) P. P. Nievergelt, M. Babor, J. Čejka and B. Spingler, Chem. Sci., 2018, 9, 3716-3722; (b) M. Babor, P. P. Nievergelt, J. Čejka, V. Zvoníček and B. Spingler, IUCrJ, 2019, 6, 145-151.

8 R. Bolliger, A. Frei, H. Braband, G. Meola, B. Spingler and R. Alberto, Chem. - Eur. J., 2019, 25, 7101-7104.

9 W.-H. Jiang, H.-Z. Zhang, G.-F. Hou, D.-S. Ma, B. Liu and Y.-H. Yu, RSC Adv., 2017, 7, 45641-45651.

10 (a) P. Diaz, J. Benet-Buchholz, R. Vilar and A. J. P. White, Inorg. Chem., 2006, 45, 1617-1626; (b) I. A. Koval, M. Sgobba, M. Huisman, M. Lüken, E. Saint-Aman, P. Gamez, B. Krebs and J. Reedijk, Inorg. Chim. Acta, 2006, 359, 4071-4078; (c) J. Suárez-Varela, A. J. Mota, H. Aouryaghal, J. Cano, A. Rodriguez-Diéguez, D. Luneau and E. Colacio, Inorg. Chem., 2008, 47, 8143-8158; (d) P. Mukherjee, M. G. B. Drew, M. Estrader, C. Diaz and A. Ghosh, Inorg. Chim. Acta, 2008, 361, 161-172; (e) L. Botana, J. Ruiz, J. M. Seco, A. J. Mota, A. Rodríguez-Diéguez, R. Sillanpää and E. Colacio, Dalton Trans., 2011, 40, 12462-12471; (f) R. A. Polunin, K. S. Gavrilenko, M. A. Kiskin, I. L. Eremenko, V. M. Novotortsev and S. V. Kolotilov, Russ. J. Coord. Chem., 2016, 42, 487-493.

11 (a) J. Fielden, P. T. Gunning, D.-L. Long, M. Nutley, A. Ellern, P. Kögerler and L. Cronin, Polyhedron, 2006, 25, 3474-3480; (b) R. Mondal, T. Basu, D. Sadhukhan, T. Chattopadhyay and M. K. Bhunia, Cryst. Growth Des., 2009, 9, 1095-1105.

12 (a) A. N. Khlobystov, A. J. Blake, N. R. Champness, D. A. Lemenovskii, A. G. Majouga, N. V. Zyk and M. Schröder, Coord. Chem. Rev., 2001, 222, 155-192; (b) X. Li, Y. Gong, H. Zhao and R. Wang, Inorg. Chem., 2014, 53, 12127-12134.

13 X.-R. Meng, X.-J. Wu, D.-W. Li, H.-W. Hou and Y.-T. Fan, Polyhedron, 2010, 29, 2619-2628.

14 Y. Mu, Y. Zhao, H. Xu, H. Hou and Y. Fan, J. Mol. Struct., 2009, 935, 144-150.

15 P. Chen, M. Zhang, W. Sun, H. Li, L. Zhao and P. Yan, CrystEngComm, 2015, 17, 5066-5073.

16 V. Bugris, C. Dudás, B. Kutus, V. Harmat, K. Csankó, S. Brockhauser, I. Pálinkó, P. Turner and P. Sipos, Acta Crystallogr., Sect. B: Struct. Sci., Cryst. Eng. Mater., 2018, 74, 598-609.

17 N. Maki, Bull. Chem. Soc. Jpn., 1969, 42, 2275-2281.

18 (a) J. Lacour, C. Goujon-Ginglinger, S. Torche-Haldimann and J. J. Jodry, Angew. Chem., Int. Ed., 2000, 39, 3695-3697; (b) A. M. Todd, A. N. Swinburne, A. E. Goeta and J. W. Steed, New J. Chem., 2013, 37, 89-96.

19 (a) J. T. Kirner and C. M. Elliott, J. Phys. Chem. C, 2015, 119, 17502-17514; (b) O. S. Wenger, Coord. Chem. Rev., 2015, 282, 150-158.

20 (a) S. Aghazada and M. K. Nazeeruddin, Inorganics, 2018, 6, 52; (b) A. Colombo, C. Dragonetti, A. Valore, C. Coluccini, N. Manfredi and A. Abbotto, Polyhedron, 2014, 82, 50-56.

21 S. Aghazada, I. Zimmermann, Y. M. Ren, P. Wang and M. K. Nazeeruddin, ChemistrySelect, 2018, 3, 1585-1592.

22 (a) M. Du, X.-J. Zhao and H. Cai, Z. Kristallogr. - New Cryst. Struct., 2004, 219, 463-465; (b) W. Liu, W. Xu, J.-L. Lin and H.-Z. Xie, Acta Crystallogr., Sect. E: Struct. Rep. Online, 2008, 64, m1586-m1586.

23 (a) T. J. Rutherford, P. A. Pellegrini, J. Aldrich-Wright, P. C. Junk and F. R. Keene, Eur. J. Inorg. Chem., 1998, 16771688; (b) J. Karges, O. Blacque, P. Goldner, H. Chao and G. Gasser, Eur. J. Inorg. Chem., 2019, 2019, 3704-3712.

24 I. Bratsos, E. Alessio, M. E. Ringenberg and T. B. Rauchfuss, Inorg. Synth., 2010, 35, 148-152.

25 R. W. Potter II and M. A. Clynne, J. Res. U.S. Geol. Surv., 1978, 6, 701-705.

26 V. L. Thurmond, R. W. Potter II and M. A. Clynne, The densities of saturated solutions of $\mathrm{NaCl}$ and $\mathrm{KCl}$ from $10{ }^{\circ} \mathrm{C}$ to $105^{\circ} \mathrm{C}$, U. S. Geological Survey, 1984.

27 (a) S. Schnidrig, C. Bachmann, P. Müller, N. Weder, B. Spingler, E. Joliat-Wick, M. Mosberger, J. Windisch, R. Alberto and B. Probst, ChemSusChem, 2017, 10, 4570-4580; (b) H. Nierengarten, J. Rojo, E. Leize, J.-M. Lehn and A. Van Dorsselaer, Eur. J. Inorg. Chem., 2002, 573-579.

28 Rigaku Oxford Diffraction, CrysAlisPro Software system 1.171.40, Rigaku Corporation, 2018.

29 G. M. Sheldrick, Acta Crystallogr., Sect. A: Found. Adv., 2015, 71, 3-8.

30 G. M. Sheldrick, Acta Crystallogr., Sect. C: Struct. Chem., 2015, 71, 3-8.

31 O. V. Dolomanov, L. J. Bourhis, R. J. Gildea, J. A. K. Howard and H. Puschmann, J. Appl. Crystallogr., 2009, 42, 339-341.

32 C. F. Macrae, L. Sovago, S. J. Cottrell, P. T. A. Galek, P. McCabe, E. Pidcock, M. Platings, G. P. Shields, 
J. S. Stevens, M. Towler and P. A. Wood, J. Appl. Crystallogr., 2020, 53, 226-235.

33 A. L. Spek, Acta Crystallogr., Sect. D: Biol. Crystallogr., 2009, 65, 148-155.

34 (a) P. Kraft, A. Bergamaschi, C. Broennimann, R. Dinapoli, E. F. Eikenberry, B. Henrich, I. Johnson, A. Mozzanica, C. M. Schlepütz, P. R. Willmott and B. Schmitt, J. Synchrotron Radiat., 2009, 16, 368-375; (b) C. Brönnimann and P. Trüb, in Synchrotron Light Sources and Free-Electron Lasers: Accelerator Physics, Instrumentation and Science Applications, ed. E. J. Jaeschke, S. Khan, J. R. Schneider and J. B. Hastings, Springer International Publishing, Cham, 2016, pp. 995-1027; (c) A. Förster, S. Brandstetter and C. Schulze-Briese, Philos. Trans. R. Soc., A, 2019, 377, 20180241.

35 L. Prieto, M. Neuburger, B. Spingler and F. Zelder, Org. Lett., 2016, 18, 5292-5295.

36 A. L. Spek, Acta Crystallogr., Sect. C: Struct. Chem., 2015, 71, 9-18.

37 S. E. Balaghi, C. A. Triana and G. R. Patzke, ACS Catal., 2020, 10, 2074-2087.
38 A. Altomare, N. Corriero, C. Cuocci, A. Falcicchio, A. Moliterni and R. Rizzi, J. Appl. Crystallogr., 2015, 48, 598-603.

39 D. J. Szalda, C. Creutz, D. Mahajan and N. Sutin, Inorg. Chem., 1983, 22, 2372-2379.

40 (a) R. A. Haines and D. W. Bailey, Inorg. Chem., 1975, 14, 1310-1312; (b) A. Tatehata, Inorg. Chem., 1976, 15, 20862090.

41 (a) R. S. Drago, B. B. Corden and C. W. Barnes, J. Am. Chem. Soc., 1986, 108, 2453-2454; (b) Y. H. Lin, I. D. Williams and P. Li, Appl. Catal., A, 1997, 150, 221-229; (c) X. Zhou and H. Ji, Chin. J. Chem., 2012, 30, 2103-2108; (d) B. Biannic and J. J. Bozell, Org. Lett., 2013, 15, 2730-2733.

42 (a) M. Atzori, A. Serpe, P. Deplano, J. A. Schlueter and M. L. Mercuri, Inorg. Chem. Front., 2015, 2, 108-115; (b) V. V. Lukov, I. N. Shcherbakov, S. I. Levchenkov, Y. P. Tupolova, L. D. Popov, I. V. Pankov and S. V. Posokhova, Russ. J. Coord. Chem., 2019, 45, 163-187.

43 ChemAxon Ltd., MarvinSketch 20.6, 2020.

44 J. C. Knight, A. J. Amoroso, P. G. Edwards, R. Prabaharan and N. Singh, Dalton Trans., 2010, 39, 8925-8936. 